\title{
Socio-economic Differentials in Birth Masculinity in China
}

\section{Christophe Z. Guilmoto and Qiang Ren}

\begin{abstract}
This article examines the relationship between birth masculinity and socioeconomic levels in China. Both 2000 and 2005 data suggest the presence of a non-linear relationship between the sex ratio at birth and socio-economic status, with a lower sex ratio at birth observed among both the poorest and the richest households. This inverted-U pattern is significantly different from what is observed in India and what has been assumed previously for China. Multivariate analyses indicate that this pattern persists after the introduction of several other covariates of birth masculinity such as ethnicity, fertility, migration status, age or parity. These results suggest that further economic advances and socio-economic mobility could contribute to the return to normalcy of the sex ratio at birth.
\end{abstract}

\section{INTRODUCTION}

The upward trend in sex ratio at birth (SRB) observed since the 1980s in several Asian countries corresponds to a new manifestation of existing gender bias (Attané and Guilmoto, 2007; Croll, 2000; Miller, 2001). The resulting change in sex structures since the 1980s is likely, two decades on, to cause a marriage squeeze of unusual severity in affected countries. Given the potential sex ratio crisis, it is of utmost importance to monitor the current process of demographic masculinization and to understand its various social and economic correlates.

Existing analyses of SRB levels and differentials in China, India and South Korea have stressed several associated factors such as regional patterning, differences between religious or ethnic groups and birth order (parity). To a large extent, regional variations in birth masculinity observed within countries such as China and India tend to reflect differences in son preference,

The collaborative work by the authors has benefited from support by CEPED, Paris. Useful comments by Isabelle Attané, Lisa Eklund and CEPED colleagues on a previous version of this paper are gratefully acknowledged. An earlier version of the paper was presented at the conference of the Asian Population Association in Delhi in November 2010. We would like also to thank Stevan Harrell and the anonymous reviewer of Development and Change for their comments and suggestions.

Development and Change 42(5): 1269-1295. (c) 2011 International Institute of Social Studies. Published by Blackwell Publishing, 9600 Garsington Road, Oxford OX4 2DQ, UK and 350 Main St., Malden, MA 02148, USA 
a feature closely related to anthropological features such as kinship systems. ${ }^{1}$ Two further dimensions also appear to be closely linked to the rise in the proportion of male births: the pressures exerted by fertility decline and birth control regulations on couples wishing to give birth to at least one son, and the growing supply of effective sex selection technology based on pre-natal diagnosis. In contrast, social and economic development which has dramatically altered the Asian landscape over the past decades may be seen as a harbinger of the future decline in gender bias as illustrated by the current decline in SRB levels observed in more prosperous South Korea. Increased prosperity and social modernization may therefore facilitate spontaneous social change towards greater gender equity that could bring about a turnaround in birth masculinity (Chung and Das Gupta, 2007).

This article explores the relationship between indicators of socioeconomic status (SES) in China and gender preferences and attitudes as revealed by levels of sex ratio at birth. Previous research based on provincelevel statistics has suggested that the sex ratio at birth in China tends to increase with socio-economic level, a phenomenon also observed in India. This could have worrisome implications in countries characterized by rapid economic growth. In this article, we will use two different sets of data to demonstrate that the relationship between socio-economic status and birth masculinity is more complex than previously assumed. While the SRB increases with socio-economic level for the first two quintiles, a reverse decline is visible among the richer groups. In other words, except for the poorest segments of China's population, better socio-economic status is associated with reduced birth masculinity. This finding may partly account for the overall SRB stagnation observed over the last decade in China coinciding with a period of rapid economic change.

Our study begins with a brief review of the current process of demographic masculinization in Asia and of the role of socio-economic differentials. We then describe the data available to study variations in sex ratio at birth and the results of the analysis of the 2005 data. The subsequent section presents the results of two multivariate analyses based respectively on 2000 and 2005 data, confirming the inverted-U pattern of the SES-SRB relationship. The article then concludes with a discussion of the policy implications of our findings.

\section{SEX RATIO AND SOCIO-ECONOMIC DIFFERENTIALS}

\section{Sex Ratio at Birth in China}

The rise in sex ratio at birth observed in China is linked to the growing number of selective abortions of female foetuses, which has been enabled by

1. The pronounced spatial patterning of child sex ratio in China is examined in Guilmoto and Oliveau (2007). For a recent historical and anthropological interpretation of these regional variations, see Das Gupta (2010). 
the spread of pre-natal screening technology (Chu, 2003; Gu and Roy, 1995; Qi and Mason, 2005; Wu et al., 2006; Zeng et al., 1993). SRB levels started to increase steadily in the late 1980 s, reaching 111.3 male births per 100 female births in 1990 and 119.9 in 2000, according to the long-form questionnaire (Gu and Xu, 1994; Lv, 2003). This high level of reported SRB has changed little since, even if a minor decline is detectable: the 2005 intercensal survey put the SRB at 120.5 and the official estimate of 119.5 for 2009 are similar while the first 2010 census estimate is 118.1 (Li, 2007; Li et al., 2007; NSB, 2010). Well-known features of SRB variations in China include regional differentials and the parity effect (Cai and Lavely, 2007; Zhang, 2005). The latter effect stems from the fact that gender discrimination is usually negligible for first pregnancies, but increases for later births. Census data also indicate that there are substantial regional differentials: several provinces to the West such as Xinjiang or Tibet appear to have been barely affected by the national trends up to 2005, while sex ratio at birth in some provinces of East or Central China has been estimated at record levels, above 130 (NSB, 2007). High SRB levels appear to be in some measure linked to the distribution of the Han majority group across the country (Attané, 2007). It should be emphasized that large disparities in birth masculinity also exist both within the Hans and across minority groups. ${ }^{2}$

\section{Socio-economic Factors and High SRB}

Socio-economic status is theoretically linked to sex ratio outcomes in various ways. Initial biological studies of worldwide variations in sex ratio at birth indicated higher proportions of male births among privileged groups, but such variations can also be attributed to foetal mortality (Chahnazarian, 1988; Teitelbaum and Mantel, 1971). But apart from estimation issues related to sex differentials in birth reporting, today's rise of the proportion of male births needs to be considered with respect to three different factors: availability of sex selection technology (supply), son preference (demand) and low fertility pressure (spontaneous fertility decline and population policies) (Guilmoto, 2009). Regarding supply variables, we should also expect a positive link as higher education and income levels tend to facilitate information about and access to modern sex selection technology. Similarly, low fertility among higher SES groups exacerbates the need for sex selection as the risk of remaining sonless rises among smaller families. This picture may be reinforced in China's case since the family planning policy tends to

2. For instance, some minority groups — such as the Zhuang — also display high levels of birth masculinity. Moreover, there are also considerable variations within Han-dominated regions: in Hubei, for example, whose population includes no less than 95 per cent of Han Chinese, sex ratio at birth was almost normal (below 110) in 2000 in 25 per cent of local counties, but reached extremely levels (above 140) in another 25 per cent of counties. 
be stricter for urban or more affluent populations. The influence of SES on demand variables (son preference) is more ambiguous. While women tend to be economically valued among the poorest families with no assets, this may be less the case in the middle of the social hierarchy, especially among landed households in which land rights are often transmitted along the male line.

Several aspects of improved individual socio-economic status tend to militate for higher SRB levels. However, unequal gender values tend to dissipate among the urban middle-classes in which women enjoy better education and employment opportunities, and gain a higher degree of autonomy in society. As a result, the existence of gender-biased norms and attitudes would be expected to weaken with social and economic modernization. This phenomenon possibly represents one of the few ways in which higher development levels and individual SES indicators could distinctly lower birth masculinity.

The relationship between socio-economic status and the proportion of male births has already been examined in other Asian countries and is often positive. For instance, disaggregated data from the recent 2009 census indicate that SRB tends to rise with SES quintile in Vietnam. ${ }^{3}$ India's case is especially revealing. Several socio-economic and developmental indicators have indeed been found to be associated with gender discrimination in India. The most detailed investigations of the 'prosperity effect' can be found in Agnihotri (2003) and Siddhanta et al. (2003) who show how expenditure levels are positively related to birth masculinity. Similarly, geostatistical analysis by Guilmoto (2007) based on the 2001 census at district level identifies economic development as one of the major correlates of high SRB, along with anthropologic composition of the population and distinct spatial processes.

India is a textbook case for a positive relationship between socio-economic status and birth masculinity. More recent data from the latest National Fertility and Health Survey (2005-06) can be used to illustrate variations by socio-economic status in a similar way to the exercise carried out for China later in this article. As with demographic and Health Surveys, the NFHS offers the standard division of households into SES quintiles. In Figure 1, we show the respective SRB levels for each quintile: the relationship between SES and SRB is strong and positive, with birth masculinity ranging from a normal level among the poorest households to levels distinctly above 115 for the highest SES strata (see also Jha et al., 2011).

3. On Vietnam, see UNFPA (2010). No clear link between high SRB and SES levels emerges from the analysis of Korean data for 1994 and 2000, even if there is a clear negative link with gender preference (Kim and Song, 2007; Lin, 2009). 
Figure 1. Sex Ratio at Birth in India by Socio-economic Quintile, 2000-06

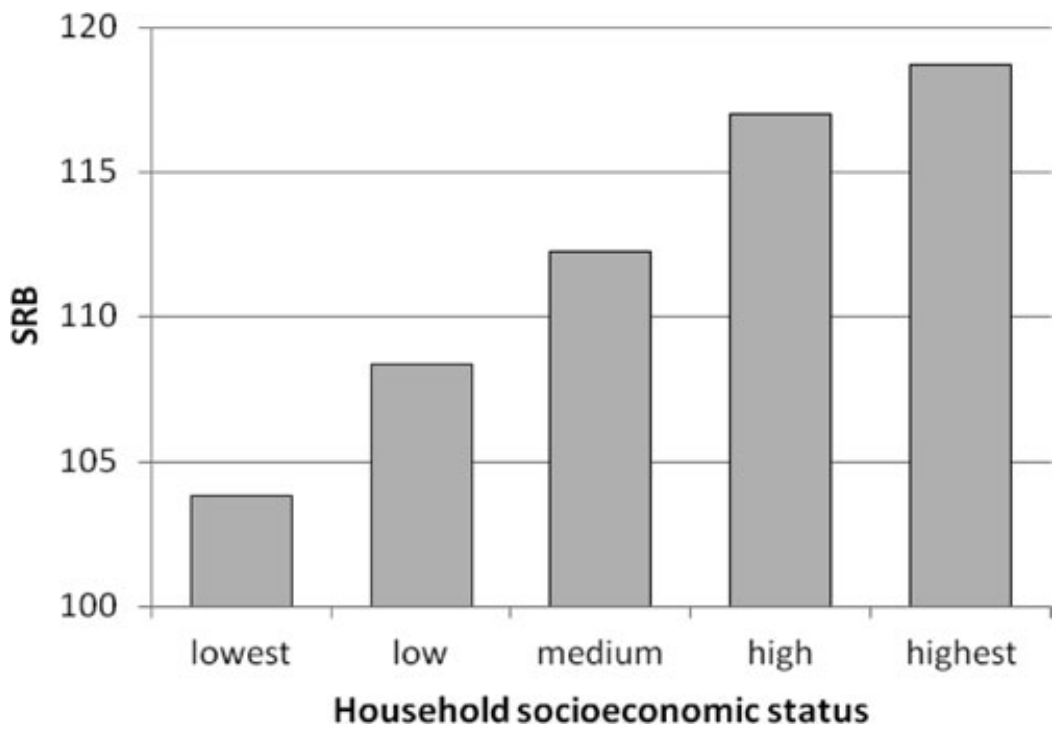

Source: calculated by the authors from NFHS-3 data.

\section{Socio-economic Factors and Chinese Sex Ratio}

In comparison, relatively little is known about the social and economic correlates of high sex ratio at birth in China. One reason is the paucity of appropriate sample data, especially as birth masculinity is influenced by a host of different factors (parity, ethnicity, residence, etc.). The inadequacy of socio-economic variables derived from Chinese surveys and censuses is another reason and, as a result, education is often used as a proxy for socioeconomic levels. The absence of appropriate analysis of socio-economic differentials is especially regrettable in view of the considerable rise in inequality observed in China since the economic reforms that were initiated during the late 1970s (Appleton et al., 2009; World Bank, 2009). With a Gini ratio of 0.49 according to the latest UNDP estimates, China has become a far more unequal country than many other Asian nations, including India (UNDP, 2005). This signals the need to relate social inequality to gender outcomes in China.

Results of previous studies on socio-economic differentials in China have been somewhat ambiguous. For instance, census data suggest that there is a positive link between SRB and education up to at least 1990 (Gu and Roy, 1995), and a regression analysis of 1990 literacy data suggests the same (Guilmoto, 2005). However, a review by Banister (2004) fails to detect the independent effect of education or income variables on sex ratio. 
Sex ratio data from the 2000 census do not lead to any clear association between education variables and birth masculinity. Summarizing available research on the causes of the preference for sons, which is a key factor behind inordinate SRBs, Tan (2008) considers economic factors to be less prominent than traditional Confucian gender attitudes, a view reinforced by a more anthropological reading of the situation across Asia (Das Gupta, 2010). Lavely and Cai (2004) have also conducted a regression analysis of sex ratio variations in 2000 , based on a restricted number of variables, with no socio-economic linkage emerging from their analysis. Some studies stressed the impact of sex differentials in infant mortality and its links with the SES of mothers, but this is not the main factor for higher child sex ratios (Han and Li, 1999; Li, 1993a, 1993b; Li and Zhu, 2001).

The relationship between SRB levels and fertility policies in China has long been debated. While some like Yuan and Shi (2005) tend to deny it, other studies strongly support the existence of such a link (Cai, 2007; Zhang, 2005; Zhu et al., 2009). Guo's multilevel analysis (2007) also concludes that fertility policies influence birth masculinity. Chen et al. (2008) further identify high SRB groups such as the populations with agricultural hukou (registration) or with lower education. But it should be borne in mind that the strict one-child policy is applied only in cities and more developed regions. Elsewhere, especially among the rural population, couples are allowed to have a second child after the birth of a daughter: as a result, the SRB among second and later births tends to be very high as sonless parents often resort to sex selection to ensure the birth of a boy. Thus, in 2005, first births had a sex ratio at birth of 108.4 as opposed to 143.2 for second births and even higher values for later births. As expected, the SRB of first births in urban areas is higher: 111.4 in towns and 109.7 in cities. This can be explained by the fact that birth-planning regulations are more drastic in urban areas, with very few couples able to have a second birth. Yet, the SRB among first births in urban areas remains modest compared to SRB levels observed for higher birth orders, showing that only a relatively small proportion of urban residents resort to sex selection during the first pregnancy. Moreover, the SRB of second births is lower among urban residents than in rural areas. These observations suggest that apart from the specific effects of fertility policies, son preference is probably less pronounced in towns and cities than in the countryside. This notwithstanding, Attané (2009) has recently presented a systematic examination of regional variations in gender discrimination based on 2000 census data. The socio-economic covariates of high SRB identified in her analysis are somewhat difficult to interpret, since they point to both a poverty effect (regional poverty and lack of health structures) and a prosperity effect (measured by higher education and increased access to the media).

In line with the general considerations outlined previously, this article argues that economic and social modernization are indeed positively linked to pre-natal discrimination and higher SRB levels in China. This implies, in particular, that the current economic development in China may act as a 
stimulus for further decreases in SRB levels. While this hypothesis may not square with the stalling of the SRB values observed over the last decade, it remains the most substantial analysis of the role played by socio-economic differentials. Our analysis based on data at a finer scale will show, however, that while socio-economic status is associated with higher birth masculinity among the poorest quintiles, prosperity tends on the contrary to be associated with lower SRB levels among better-off social groups. In other words, beyond other important factors - such as anthropological differences accounting for the spatial patterns of SRB - further socio-economic upliftment in the country may reduce pre-natal discrimination against girls in the future.

\section{DATA AND MODEL SPECIFICATION}

\section{Data and Variables}

In the absence of exhaustive birth registration statistics for China, our SRB analysis relies on the census and survey data. Census tabulations refer either to age or sex population distributions, but provide very little detail for in-depth analysis. Sample survey datasets offer richer materials to study the predictors of birth masculinity but the sensitivity of SRB calculations to sample size is a potential weakness of sex ratio analysis. ${ }^{4}$ In this study, we use data from the 2000 census and the 1 per cent intercensal survey of 2005 - two sources corresponding to a time period characterized by apparent stabilization of SRB levels in China. The 2000 census and the 2005 survey are almost identical in design and content, except for a few variables introduced in 2005 - such as migration status and social insurance - and a new definition of 'current residence', which is closer to the 'de facto' approach. But the format in which they will be processed is different. ${ }^{5}$ Data from the 2000 census refer to tabulations by county (xian), the lowest administrative level available in the census. Variables used for 2000 therefore refer to county average values such as age-specific sex ratios or minority population percentage. ${ }^{6}$ The 2005 data are, in contrast, based on individual and household data. The 2005 subsample used in this article was systematically extracted with interval sampling by the Chinese National $\mathrm{Bu}-$ reau of Statistics from the original data of the 1 per cent national survey

4. For instance, the 5 per cent confidence interval of a SRB of 105 computed over 10,000 births ranges between 101 and 109 .

5. There are no similar datasets from both 2000 and 2005 surveys to carry out a directly comparable analysis: 2005 data are not provided at county level, while no appropriate individual sample from the 2000 census is available.

6. In 2000, China was divided into province-level units, prefecture-level units and counties. Counties had an average county population of 438,000 inhabitants. For our analysis, 2,368 counties are available. 
conducted in 2005. It includes 2,585,481 persons - about 2 per 1,000 of China's population. From this subsample, we created a new sample of 24,898 recent births, containing all particulars related to individual births (such as sex and parity) as well as those of the mothers and their corresponding households.

The key variable used in our analysis is the sex ratio at birth available from the 2005 birth sample. For the 2000 data, it is measured as the sex ratio below one year of age, an indicator slightly influenced by sex specific differentials in child survival. Several independent variables used in the regression analysis are available from both sources (see the variable description in the Appendix). Indicators available only for the 2000 counties include, for instance, age structure, proportion of divorcees, and proportion of multigenerational households or county-level demographic indicators. In contrast, information such as parity or previous births, or a detailed description of housing and amenities, is only available from the individual 2005 sample. In order to make results comparable, our final statistical analysis is mostly restricted to domains covered in both sources.

Some variables may also be poorly specified or, conversely, too detailed, as for social and economic variables. For instance, we have a large number of variables describing housing or socio-economic characteristics of individual counties. Similarly, no less than twenty-eight variables describe county-level educational characteristics, and another fifteen variables pertain to marital status. In such cases, we have performed a preliminary factor analysis in order to synthetize the raw variables. For county averages from the 2000 census, we have relied on standard principal component analysis (PCA). Starting with a set of variables linked to a common domain, we construct a synthetic indicator based on the first factorial dimension - accounting usually for more than 60 per cent of the overall sample variance. This method's most useful application is the construction of a single index of socio-economic status (SES) from some forty-nine available independent variables: twenty-four variables detailing education levels, and twenty-five variables on employment status, work sector and occupation. The resulting first component accounts for more than half of the total variance with an eigenvalue of twenty-five. Other county-level variables were also aggregated to construct three additional factor scores for multigenerational households, population ageing and divorced or remarried population. ${ }^{7}$

Principal component analysis, however, is inappropriate for the 2005 individual sample, in which many variables are dummy or qualitative variables. We have therefore used the multiple correspondence analysis (MCA), a

7. These three factor analyses were based on the following three different subsets of 2000 county variables: four variables describing the percentages of multigenerational households; four variables related to the presence of population aged above sixty-five in the household; and four variables describing the proportions of divorced and remarried populations among men and women. Details on the factor analyses are available from the authors. 
technique tailored to analyse the relationship pattern between categorical variables (Abdi and Valentin, 2007). The computation of the SES indicator is based on the following four categorical variables: education level (seven values), occupation (seven values after reclassification of the original sixty-five survey categories), salary (reclassified in six categories) and social insurance. Insurance is included in the SES indicator in view of both its correlation with other socio-economic variables and its link with SRB variations illustrated below. The first MCA factor, which accounts also for more than half of the sample variance, has been retained as synthetic indicator of socio-economic status for the mothers of the 2005 sample. $^{8}$

\section{Statistical Analysis}

The dependent variable is the sex ratio at birth, computed as county-level average (2000 county data) or a dichotomous variable (2005 birth sample). For 2000, we will model SRB variations with a standard OLS regression, in which the average sex ratio levels are correlated with other variables for the 2,368 available counties. While such regional ('ecological') analyses are not without limitations (Steel et al., 2006), they provide the main sources for comparative analysis of SRB determinants in various settings (Guilmoto, 2008; Kim and Song, 2007; Lavely and Cai, 2004). Our model is similar to that used in Attané's (2009) study, though her analysis is restricted to thirty provincial units - a scale we consider unsuitable in view of the provinces' size and inner SRB heterogeneity.

For the 2005 individual birth sample, we use a loglinear (logit) analysis to model the occurrence of a male birth, using the additional variables related to the mother and household as covariates as was done with India (Bhat and Zavier, 2007; Retherford and Roy, 2003). The main drawback of this method is that the probability of male birth is only marginally affected by social causes such as gender discrimination. In the absence of sex selection, the sex of most births remains chiefly random. The contribution of sex selection to the overall variance of birth masculinity is therefore modest since a majority of parents do not practise it. With less than 25,000 recent births in our sample, the logit modelling of the occurrence of a male birth can be expected to be far less robust than linear regression analyses of SRB variations at county level.

\section{SOCIAL AND ECONOMIC VARIATIONS IN BIRTH MASCULINITY}

This section comprises the results of the statistical analyses of sex ratio variations in China based on the two different datasets. Some findings for 2005 confirm SRB differentials already known from the tabulations published by

8. Two socio-economic indicators (insurance and salary) used in the 2005 factor analysis of SES characteristics are not available from the 2000 county tabulations. 
Table 1. Sex Ratio at Birth According to Selected Variables in China, 2005 Subsample

\begin{tabular}{lc}
\hline Variables & Sex ratio at birth (SRB) \\
\hline Birth parity & \\
First birth & $108.0^{* * *}$ \\
Second birth & $140.6^{* * *}$ \\
Third or subsequent birth & $156.4^{* * *}$ \\
No previous male birth (all women) & $123.7^{* * *}$ \\
No previous male birth (with parity $>1)$ & $192.8^{* * *}$ \\
Characteristics of mother & \\
Ethnic minority & $111.3^{* *}$ \\
Residence in city & $114.8^{* *}$ \\
West China & $111.8^{* * *}$ \\
Migrant & $133.7^{* *}$ \\
Status in household & $112.5^{*}$ \\
Land-based occupation & $122.5^{*}$ \\
Insurance & $112.6^{* * *}$ \\
Housing characteristics & \\
Housing with less than 3 rooms & $115.0^{* *}$ \\
Housing shared by multiple households & $132.4^{* *}$ \\
Housing with no running water & $122.5^{* *}$ \\
Housing with gas or electricity used for cooking & $115.0^{*}$ \\
Housing with modern individual toilet & $112.0^{* *}$ \\
Housing with modern bathroom & $115.5^{* *}$ \\
\hline
\end{tabular}

Note: ${ }^{* * *} \mathrm{p}<0.01 ;{ }^{* *} \mathrm{p}<0.05 ;{ }^{*} \mathrm{p}<0.10$.

the Chinese Bureau of Statistics. Other results presented here are new, because they are based on specific individual or household variables that have not previously been used in sex ratio analysis. ${ }^{9}$

\section{SRB Differentials in 2005 with Individual and Household Variables}

Table 1 brings together some of the most interesting variations observed from the 2005 sample and also features the significance level derived through a chi-square test. ${ }^{10}$ The parity effect is one of the most common dimensions of SRB differentials in Asia. As reported in the 2005 original tabulations, birth masculinity at 108 is almost normal for first births in China, but jumps to 141 for second-order births and to 156 for subsequent births (which are, however, far less frequent). Using details of the mother's birth history, it is also possible to underscore here the specific role played by the absence of a previous male child as described in previous studies: in our sample, the SRB jumps to 193 for second and higher parity among mothers with no son. We also observe that the curve of SRB by mother's age follows a

9. For studies using the 2005 sample, see NSB (2008).

10. Variables without significant SRB differentials and collinear variables are not shown in this table. 
typical inverted-U profile, peaking above 125 male births per 100 female births before the age of thirty.

The lower SRB figure observed in cities points not only to the higher proportion of first-order births, but also to a lesser intensity of son preference, as previously indicated. The number of ethnic groups and provincial units in China prevents us from attempting a detailed analysis based on our sample, but the SRB is distinctly low in minority (non-Han) groups, and less developed provinces in the west of the country, features already observed in 2000 (Banister, 2004; Cai and Lavely, 2007).

One characteristic that is less often examined for want of appropriate data is the migration status of the mother, which may be better captured in the 2005 sample survey than the 2000 census because of the new definition of residence. Our results demonstrate that migrant mothers, namely women who moved in from a different locality over the last five years, report a very high sex ratio at birth (134). Even if the proportion of migrants among recent mothers amounts to less than 7 per cent of our subsample, this difference appears significant. Some mothers may be able to give birth to boys because they are migrants and manage to escape stricter fertility limitations or prohibitions on sex selective abortions in their home community. Higher birth masculinity may also reflect the migrants' social vulnerability and stronger dependence on a patriarchal household system. Another hypothesis would relate the higher SRB level among migrants to a corresponding higher level of underreporting of female births. Our database does not, however, allow for testing further hypotheses on the exact causes of this high SRB level among migrants. Another interesting finding of our analysis is the moderate SRB level (112.5) observed among mothers who are neither the wife nor daughter-in-law of the household head, but household heads or married daughters living with their parents. This indirectly points to various less common gender arrangements - ranging from uxorilocal family systems to female-headed households. Such configurations have long been associated with women's greater autonomy and higher status, features that are also related to lower levels of gender discrimination ( $\mathrm{Li}$ et al., 2000; Ma, 1997).

\section{Socio-economic Differentials Related to Sex Ratio at Birth}

This section focuses on some lesser-studied socio-economic characteristics of parents and their relationship to SRB variations. Table 1 shows sex ratio to be slightly higher among households with no access to running water and this association of SRB with poverty is also observed from 2000 data by Attané (2009). But this initial conclusion appears somewhat misleading, since all other household indicators in the analysis point to a rather different relationship. For instance, lower SRB values are found among children born in households with modern amenities such as individual toilets (112) or a 
bathroom with hot water (115.5). In fact, almost all features typical of better housing - such as private apartment, gas or electricity used for cooking, modern toilet and bathroom - correspond to populations with lower SRB levels. ${ }^{11}$ This apparently negative relationship between masculinity of births and living standards is confirmed when the education and employment of the mother are included: higher education and better occupation are also linked to lower SRB levels.

The standard list of occupations and job positions provides somewhat inadequate variables to capture social stratification. In contrast, the new variables on the type of social insurance benefits have proved extremely meaningful for our analysis. In this regard, it should be stressed that the deep restructuring of China's economy since the 1980s involved a dramatic reduction in state sector jobs and that the protection system had to be entirely revamped (Selden and You, 1997). Several new social programmes were initiated such as the Di Bao system for guaranteeing basic life necessities (World Bank, 2009). In the 2005 survey, workers were asked if they participated in three different social insurance programmes: pension, unemployment and medical insurance. ${ }^{12}$ Table 1 indicates that mothers benefiting from at least one of these insurance programmes display one of the lowest SRB levels observed in our sample. This parallels results from a study of the rural pension programme. ${ }^{13}$ It should be kept in mind at this juncture that the majority of workers in today's China retire without any form of pension and that rural workers are especially disadvantaged in this regard. In 2008, only 166 million workers participated in the basic pension programme while some 124 million people had unemployment insurance (NSB, 2009). Half of the elderly in rural areas depend primarily on family support. Health care coverage was also rather infrequent at the time of the surveys (World Bank, 2009). ${ }^{14}$ While the number of participants in new social insurance programmes is growing rapidly, especially since the reforms introduced in 1997, they still correspond to a relatively small share of the workforce and the system is still in its infancy in the countryside, with less than 15 per cent of rural workers covered (Nielsen et al., 2005; Salditt et al., 2008). Children still offer the main source of security for the old age population, especially since the 1996 law on the elderly clearly stipulated children's obligation to provide economic support for their parents.

11. On recent trends in housing inequality in China, see Wang (2003).

12. Other important programmes found in both rural and urban areas include work injury insurance, maternity insurance, and the Di Bao social assistance programme (World Bank, 2009).

13. Ebenstein and Leung (2008) interpret the participation in pension programmes as a consequence of sonlessness. See also Bhattacharjya et al. (2008).

14. The newly introduced rural pension scheme (Xin Nongbao) may rapidly improve the situation (O'Keefe and Wang, 2010). 
A slightly higher SRB estimate is also observed among women working in the agricultural sector. The importance of male progeny may therefore vary by employment sector and status. It is particularly crucial to distinguish the gender attitudes of peasant households from those of urban workers enjoying better employment guarantees. This in turn can be related to the varying nature of Chinese family systems and to the labour contribution of male children. Sons in rural areas where the patriarchal system is stricter are likely to work jointly on land with their parents (Bossen, 2007). Conversely, gender obligations within the household tend to weaken in other sectors of the economy: in non-agricultural families from the more modern, organized sector, parents tend to rely less on their sons for the welfare of the household or for future old-age support. The reasons for this may be twofold: on the one hand, the contribution from grown-up children is of lesser importance in the more individualistic setting of a modern economy, often characterized by the existence of insurance schemes as mentioned previously. Dependence on sons is thus likely to be weaker. In addition, individual economic capacity and household rights may also become less gender-asymmetrical in modern urban sectors. In such cases, women's improved status and economic position may gradually undermine age-old son preference based on traditional gender arrangements.

The most visible aspect of this transition lies in the transformations of the family structure and living arrangements, corresponding in particular to the lower frequency of multigenerational households in urban areas (Zeng and Wang, 2003). An additional illustration of such trends may be found in the 41 per cent of urban women who declared in 2000 that family property should be equally divided between sons and daughters (as opposed to 18 per cent of rural women) rather than preferentially given to sons (NSB, 2004). While inheritance in the countryside is often based on local customs and tends to favour sons, urban residents are more likely to resort to the existing legislation such as the new 1985 law promoting gender equity in order to ensure their rights to family property (Sheng, 2005).

\section{The Non-linear Effect of SES Class on Sex Ratio at Birth}

The two SES indicators derived from the 2000 and 2005 sources confirm the rather complex relationship prevailing between socio-economic status and $\mathrm{SRB}$ levels. Each sample has been divided into five socio-economic quintiles and the average SRB values (after proper demographic weighing) of each quintile are plotted in Figure 2 separately for 2000 counties and 2005 women.

These two charts are somewhat remarkable for several reasons. First of all, they show the existence of almost parallel effects of SES ranks on SRB levels in 2000 and 2005. This is all the more noticeable considering that SES indicators for 2000 and 2005 have been computed using different factor 
Figure 2. Sex Ratio at birth in China by Socio-Economic Quintile,

2000 (Counties) and 2005 (Women)

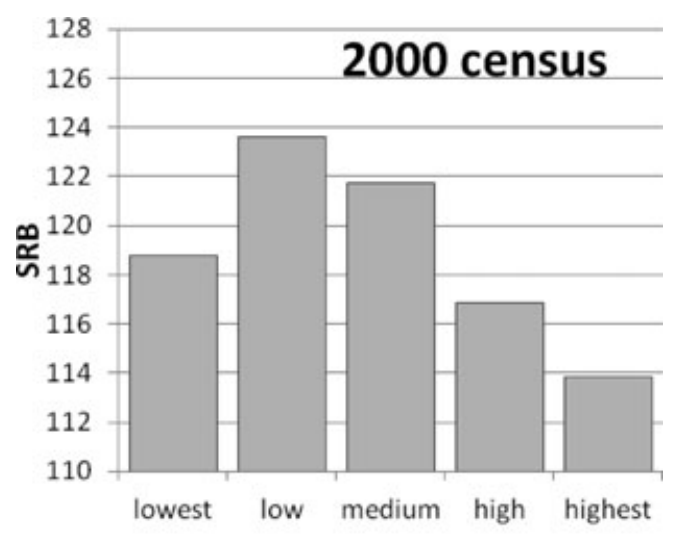

Socioeconomic status of counties

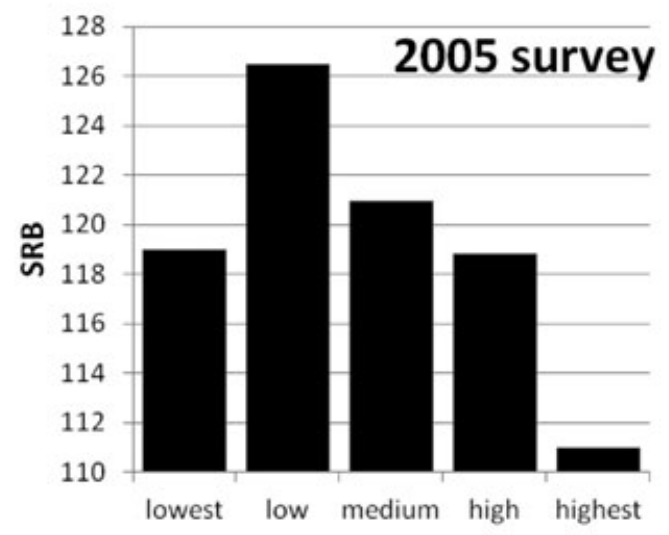

Socioeconomic status of women

analysis techniques. Moreover, the two partitions in SES quintiles compared in this figure are different since we have ranked counties in 2000 and women in 2005. But for both sets of data, the relationship appears similar. In addition, the somewhat smoother variations among county quintiles depicted in the 2000 chart of Figure 2 - compared to the wider fluctuations in the 2005 series (with SRB ranging from 111 to 126) — can be explained by the fact that counties are more heterogeneous and always include very poor or very rich households.

The second important point is that this relationship appears to be nonlinear, a trait already hinted at in our preliminary discussion. Figure 2 demonstrates the initial jump in SRB values from the first SES quintile 
to the second quintile. In fact, the lower SRB among the poorest quintile corroborates the low value reported in the 2003 Rural and Urban Household Surveys (World Bank, 2009: 177). The apparent increase in the first two SES quintiles may result from specific factors, since poverty in China coincides to a large extent with the remote uplands to the west of the country, with little industrialization, lower urbanization levels, few natural resources, poor land and minority populations (Fan and Sun, 2008). Several other factors such as higher fertility, the absence of strict birth regulations and cultural features of non-Han populations are indeed related both to low preference for sons and to higher poverty levels.

The SRB appears to be at its highest among the second quintile, a group that includes a large number of the poor Han peasants. From the second SES strata for 2000 and 2005, SRB declines continuously as the socio-economic status of counties or women improves. In both curves, SRB decreases from its highest values (124 and 126, respectively) in the second quintile to the lowest values (114 and 111, respectively) in the top quintile. While sex ratio at birth remains above the biological level among the richest, there is a pronounced difference from other SES groups, indicating the reverse effect of prosperity on birth masculinity.

This figure serves as a helpful summary of a somewhat confused situation in which the ultimately positive role of socio-economic status on gender equity is partly concealed by the effect of regional under-development in the Western provinces. It also confers upon upward socio-economic mobility a pivotal role in birth masculinity, generating an initial increase in SRB levels, followed further along the social scale by a gradual decrease in gender discrimination.

\section{Multivariate Models of SRB Variations in 2000 and 2005}

The associations between SRB levels and individual, household or county characteristics highlighted so far provide a large number of indications as to the heterogeneous distribution of birth masculinity in China. But given the risk of multicollinearity, a multivariate analysis is required to better assess the independent contribution of these factors to SRB variations and to check in particular if the association between SRB and SES may be due to other factors such as policy fertility, ethnicity or rural/urban differentials.

The ordinary least-square regression is used to model the variations in 2000 county SRB levels while the analysis of the 2005 subsample is based on a logit model of the probability of a male birth. Results are shown in Tables 2 and 3 . The only non-census variable added here is the official fertility norm (policy fertility) as calculated by Gu et al. (2007), a figure quantifying provincial variations in birth regulations. The logit analysis of the 2005 births appears more fragile and several variables are only weakly correlated to the occurrence of a male birth due to the limited size of our birth sample.

Our multivariate model confirms the role of several variables that had already been identified in the previous analysis. For instance, the 2005 model 
Table 2. Multivariate Regression Analysis of Variations in Sex Ratio Below One Year of Age, Chinese Counties, 2000 Census

\begin{tabular}{lc} 
Explanatory variables & Coefficient \\
\hline Ethnic minority & $-.066^{* * *}$ \\
Urban & $4.102^{* *}$ \\
Migrants & 11.827 \\
Multigenerational household & $-.635^{* *}$ \\
Household members above 65 & .429 \\
Divorced and remarried & $-2.455^{* * *}$ \\
County-level fertility & $3.119^{* * *}$ \\
Policy fertility & $-4.366^{* * *}$ \\
First SES quintile & $-1.755^{*}$ \\
Third SES quintile & $-1.899^{* *}$ \\
Fourth SES quintile & $-5.359^{* * *}$ \\
Fifth SES quintile & $-8.902^{* * *}$ \\
Constant & $121.850^{* * *}$ \\
$\mathrm{~N}$ & 2,368 \\
$\mathrm{R}^{2}$ & .1474 \\
\hline
\end{tabular}

Note: Variables described in Appendix; ${ }^{* * *} \mathrm{p}<0.01 ;{ }^{* *} \mathrm{p}<0.05 ;{ }^{*} \mathrm{p}=0.10$.

Table 3. Logit Model of Probability of Male Birth, Sample from the Chinese 2005 Intercensal Survey

\begin{tabular}{lc}
\hline Explanatory variables & Coefficient \\
\hline Demographic characteristics & \\
Age & $.05487^{* *}$ \\
Age (squared) & $-.0011^{* * *}$ \\
Birth parity & $.4264^{* * *}$ \\
Parity & $-.6562^{* * *}$ \\
Previous male birth & \\
Mother's characteristics & -.0517 \\
Minority & -.015501 \\
Urban & .1054 \\
Divorced or remarried & $.1392^{* * *}$ \\
Migrant & \\
Regional fertility & $-.1942^{* * *}$ \\
Policy fertility & $.08612^{*}$ \\
Province-level fertility & \\
Socio-economic status (SES) & $-.0737^{*}$ \\
First quintile & -.017 \\
Third quintile & -.0440 \\
Fourth quintile & $-.0837^{* *}$ \\
Fifth quintile & $-1.0176^{* * *}$ \\
Constant & \\
Model fit statistics & 24,898 \\
n & -16982 \\
Log likelihood & 0.0105 \\
Pseudo r & \\
\hline
\end{tabular}

Note: Variables described in Appendix Table A1; ${ }^{* * *} \mathrm{p}<0.01 ;{ }^{* *} \mathrm{p}<0.05 ;{ }^{*} \mathrm{p}=0.10$ 
shows that age retains an independent, non-linear impact on SRB, even when the parity effect is accounted for. Both younger and older mothers give birth more frequently to girls than women in the central child-bearing age groups. As expected, parity and an absence of previous male offspring also remain strongly correlated to high SRB across all women.

The local impact of birth control policies is potentially considerable in view of the importance of the Chinese government's intervention in family planning (Greenhalgh and Winkler, 2006; Scharping, 2003). This provincial level of fertility regulations is strongly statistically correlated to SRB in both models, as shown in other studies (Guo, 2007; Zhang, 2005): in areas with the strictest birth limitations, SRB is shown to be significantly higher than elsewhere. This confirms the overall impact of population policies implemented by regional authorities upon the extremely high levels of birth masculinity observed in several areas of East China. Limitations on second or later births act as a further pressure to abort unwanted pregnancies among parents who insist on having at least one son. ${ }^{15}$ Once fertility regulations are factored in, fertility levels - measured as the local total fertility rate (TFR) level in each regression - are positively associated with high SRB. This means that whenever fertility regulations are poorly enforced and fertility higher than expected, the overall proportion of male births tends to increase, a testimony to the patriarchal drive behind higher fertility.

The frequency of multigenerational households is significantly associated with low SRB in 2000, but this variable is not available for 2005. The frequency of divorce and remarriage is also significant in 2000, but is not significant in the 2005 sample. This suggests that it is not so much the single status of divorcee or remarried which reduces SRB, but rather the regional frequency of divorce and remarriage. Divorce has long been culturally discouraged in traditional Chinese society and remained rare until the early 1980s (Zeng, 2002; Zhang and Gu, 2007). Higher frequencies of divorce and remarriage in Chinese counties therefore reflect the pace of social change in Chinese society and should be read as a sign of the emergence of less traditional family arrangements, which are probably less burdened by age-old patriarchal values favouring male progeny.

Several social and geographical characteristics remain good predictors of the overall SRB level, but their impact varies in our two models. For instance, the minority variable is no longer significant in the multivariate model for 2005 although it remains strongly associated with low birth masculinity in 2000 counties. Interestingly, urbanization in 2000 and individual migration status in 2005 are significantly correlated to high SRB. The

15. However, no peak has been detected in areas with TFR around 1.5 children, where second births are conditional on the first birth of a daughter. 
latter observation ${ }^{16}$ confirms the relationship between residential mobility and birth masculinity already illustrated in a migration study conducted in Shenzhen by Wu et al. (2007). The specific position of unregistered migrants - people with rural or agricultural hukou — is characterized by a trade-off between freer geographical and economic mobility, and a loss of access to public goods and entitlements. ${ }^{17}$ This means in particular that by moving to cities, migrants may escape close administrative monitoring of their demographic behaviour and their compliance with fertility regulations is more difficult to ensure. Moreover, urban migrants are usually excluded from the social insurance benefits such as pension or unemployment guarantees that, as we have seen, are closely associated with low SRB levels (Nielsen et al., 2005; World Bank, 2009). The rapid increase in spatial mobility and in the corresponding volume of the 'floating population' is one of the most characteristic features of China's new demographic regime (Fan, 2008b; Zhao and Guo, 2007).

Turning to socio-economic status and birth masculinity, we use here the SES quintile shown on the previous charts (the second quintile with the highest SRB level is taken as a reference group). Its link with SRB previously emphasized is confirmed in our multivariate modelling. It retains its curvilinear dimension in both models, even though the correlation is more pronounced for the 2000 county sample than for the birth sample. This effect remains present independently of other social and demographic variables. ${ }^{18}$

\section{Synthesis of Findings}

The objective of this article was to use a newly released sample from the 2005 survey in China to revisit the relationship between demographic masculinization and socio-economic stratification. We embarked on this study with some feelings of uncertainty, if not frustration, owing to the rather ambiguous findings of previous studies on the nature of the linkages between pre-natal gender discrimination and the rapid socio-economic transformations of Chinese society. Contrary to the rather straightforward conclusion of studies devoted to India, research on the socio-economic determinants of higher sex ratio at birth in China has led to a complex, if not somewhat perplexing, picture in which enhanced discrimination is at times linked to indicators of both poverty and prosperity.

In our analysis, we have endeavoured to use new and more disaggregated data. One of our starting hypotheses was that the relationship was mediated by a host of other factors, such as the demographic context of mothers

16. County-level interprovincial migration is also associated with high SRB, but the coefficient is no longer significant when the urban variable is included.

17. On unregistered urban migration, see Fan (2008a) and Solinger (1999).

18. For collinearity reasons, the model for 2005 does not include the insurance variable since it has already been included in the SES indicator. 
with no previous male offspring, the geographically intricate patterns of gender discrimination, and the effect of local birth control policies. The inter-provincial migration factor has emerged along the way as an additional correlate of high sex ratio at birth, suggesting that the specific demographic behaviour of migrants should be further investigated. In view of the wide income differentials between rural and urban households, at a ratio of 1 to 3.3 in 2008 (NBS, 2008), the share of migrants in cities is unlikely to falter in the future and may further inflate urban SRB levels. Another interesting variable concerns social insurance, as progressive decline in birth masculinity appears closely associated with the various insurance schemes that were introduced in the 1990s after the demise of the so-called 'iron rice bowl' system (guaranteed employment in the state sector and social security) (World Bank, 2009). These findings therefore point to the potential contribution of structural transformations (migration, social protection) accompanying China's rapid economic growth to the changing levels of sex ratio at birth in the country.

The most interesting finding is that the relationship between socioeconomic status and birth masculinity is not linear, a feature explaining some of the inconsistent statistical associations noted in previous research on these issues. This contradicts the positive impact of socio-economic status on the intensity of SRB distortions posited in the past. As the confirmation of an inverted-U association requires strong empirical support, we added to the analysis of the 2005 birth sample a county-level analysis of SRB variations in 2000. Both statistical analyses confirm the more complex process in which socio-economic status in China influences discriminatory behaviour. The very first step out of poverty corresponds to a rapid increase in the proportion of male births, even when other important demographic or ethnic variables are controlled for. But birth masculinity peaks among the lower peasantry in rural areas, and any further increase in social status is then associated with lower SRB levels, i.e. greater gender equity and a less pronounced son preference. This explains in particular why the lower fertility observed in urban areas - due in part to stricter birth planning regulations - does not result in higher levels of pre-natal sex selection among the first births.

The divergence between China and India (Figure 1) in terms of SES-SRB interactions could hardly be more striking. SRB in China peaks for the second quintile while in India the SRB is at its highest in the richest quintile. These variations reflect of course the imperfect comparability of socio-economic quintiles across countries: the lower SES segments of India's population are significantly poorer than China's corresponding segments. This is also true of differences in fertility levels. But comparison of China with India also helps to reframe our analysis in a historical perspective. Deteriorating sex ratios should be interpreted as a cumulative or path-dependent process within regions and countries, akin to innovation mechanisms used to describe the progression of fertility decline (Casterline, 2001). One of the characteristics 
of transitional patterns is that they affect different social groups at different periods. Hence, average SRB values combine the distinct trajectories of regions and social groups. ${ }^{19}$

Demographic masculinization as a process could be divided into two different stages. During the first stage, when the new sex selection technology made its appearance in Asia, it was first appropriated by higher SES groups before spreading to the rest of society. This typical pattern of top-down propagation may be due first of all to supply and low fertility factors, which corresponds closely to the case of India. It may also apply to China until the 1980 s, in view of an initially positive link observed between literacy and SRB. During the second stage, the new discriminatory behaviour spreads progressively to other social groups because of easier access to sex selection and further fertility decline. But at the same time, the SRB may ultimately begin to return to normalcy among the more prosperous social classes who give up the patriarchal structure typical of the traditional rural economy. This accounts for the negative relationship between birth masculinity and socioeconomic status among the four richest quintiles observed in China. This also corresponds roughly to South Korea's pathway. More importantly, our results suggest that socio-economic status may emerge as a key variable for interpreting the downturn in SRB levels recently detected in several Asian countries including China (Das Gupta et al., 2009; Guilmoto, 2009).

\section{CONCLUSION: POLICY IMPLICATIONS}

In spite of the importance of future gender imbalances, the roots of the current SRB stagnation and of its potential decline in China are still poorly understood. In this final section, we will reflect on the three intermediate variables of sex selection - viz. low fertility, access to sex selection technology and gender preference - to assess their contribution to changes in birth masculinity in China and their sensitivity to policy initiatives.

The fertility factor will probably not have a positive role on birth masculinity levels in the future, unless family planning regulations are completely relaxed in China (Zeng, 2007). Currently, one of the more liberal provisions of the fertility policies is to allow a second pregnancy in rural areas following the birth of a girl (Zhang, 2005). If more people were allowed to have a second child, this would firstly result in a higher birth rate, but this may not correct at all the current inordinate sex ratio at birth if son preference remains entrenched. As far as 'supply factors' are concerned, it is also difficult to imagine that any restriction on access to sex-selective abortions could have

19. A longitudinal approach to SRB changes within given regions or social groups would be necessary to provide additional confirmation. One rare such study shows that the initial rise and subsequent decline in birth masculinity took place earlier in South Korea among higher SES groups (Chun et al., 2009). 
a sizeable impact on birth outcomes. After all, pre-natal sex determination has long been prohibited in China (Li, 2007; Tan, 2008; Zheng, 2007). As early as 1994, the national law on Maternal and Infant Health Care clearly stipulated that pre-natal sex identification was forbidden for non-medical reasons. This interdiction was reiterated over the years in several legislations affecting family planning administration and the national population policy ${ }^{20}$ but with no clear effect on gender discrimination and the overall SRB level. The reason for this poor impact lies in the lack of effective enforcement. Behind this relative failure to halt sex selection lies also the basic political contradiction between the need for fertility regulations and the fight for gender equity, in which birth control objectives have long received priority in China and hindered efforts in other domains (Greenhalgh and Winkler, 2005).

Finally, the 'demand' component of sex selection could become the main force behind any long-term decline in sex ratio at birth. It is only when the need for a son declines among the population that birth masculinity is likely to return to its normal biological level for good. But behind the preference for sons, there is a large array of cultural, social and economic aspects that are themselves susceptible to exogenous transformations, be they the structural impact of societal transformations in China or the interventions targeted at discriminatory attitudes and practices. Among the latter, the Care of Girls campaign features prominently because it combines economic initiatives to correct gender inequality and an effort to instil new gender values. The impact of this still recent project and its overall costs remain to be assessed in order to gauge its actual effectiveness in lowering sex ratios (Eklund, 2011). But what the findings of our study indicate is that improving living standards and providing better social insurance may constitute a substantial lever for change in gender attitudes in China. ${ }^{21} \mathrm{~A}$ specific structural factor is educational progress. Recent projections of human capital in China document the irreversible effect of age structures on the educational revolution taking place in China (Samir et al., 2008). If education levels remain associated with gender attitudes in the same way that SES groups are, cohort replacement will by itself bring new generations with higher educational attainment into the adult age groups. In the long run, this may bring down birth masculinity.

Our findings are based on indirect measurements of socio-economic status and on a limited birth sample for 2005. They need to be further tested, especially with results from the 2010 census. Furthermore, the fact that birth masculinity among the highest SES quintile in China today is well above the biological standard demonstrates that the decline in sex ratio is far from over.

20. The prohibition and related penalties feature in articles 35 and 36 of the Population and Family Planning Law of the People's Republic of China promulgated in 2001.

21. This corroborates the preliminary analyses of the South Korean SRB decline (Chung and Das Gupta, 2007; Lin, 2009). 
Without the involvement of government or civil society organizations, and greater access to social security and retirement benefits in the countryside, the return to normalcy of birth masculinity will take many more years.

\section{APPENDIX}

Table A1. Variables used in the Analysis of the 2000 Counties and of the 2005 Birth Sample

\begin{tabular}{|c|c|c|}
\hline Variable description & Value and unit & Dataset \\
\hline Sex ratio below one & Boys per 100 girls & 2000 \\
\hline Minority population & $\%$ of the population & 2000 \\
\hline Urban population & $\%$ of the population & 2000 \\
\hline Migrants (interprovincial) & $\%$ of the population & 2000 \\
\hline Multigenerational household & PCA factor score* & 2000 \\
\hline Household members above 65 & PCA factor score* & 2000 \\
\hline Divorced and remarried population & PCA factor score* & 2000 \\
\hline County-level fertility & 2000 TFR & 2000 \\
\hline Policy fertility & Children per woman & Gu et al. (2005) \\
\hline Socio-economic status (SES) & PCA factor score* & 2000 \\
\hline SES quintile & PCA factor score* & 2000 \\
\hline Male birth & Dummy & 2005 \\
\hline Minority & Non Han ethnic group & 2005 \\
\hline Residence in city & Dummy & 2005 \\
\hline Age & Age of the mother & 2005 \\
\hline Age squared & & 2005 \\
\hline Parity & $1,2,3+$ & 2005 \\
\hline Previous male birth & Dummy & 2005 \\
\hline West China & West China vs. East and Central China & 2005 \\
\hline Migrant & Has moved since 2000 & 2005 \\
\hline Status in household & $\begin{array}{l}\text { Neither spouse nor daughter of the } \\
\text { household head }\end{array}$ & 2005 \\
\hline Land-based occupation & Works on land & 2005 \\
\hline Insurance & $\begin{array}{l}\text { Any type of social insurance } \\
\text { (unemployment, medical, pension) }\end{array}$ & 2005 \\
\hline Modern, individual toilet type & Dummy & 2005 \\
\hline Bathroom with warm water & Dummy & 2005 \\
\hline Divorced or remarried mother & Dummy & 2005 \\
\hline Socio-economic status (SES) & MCA factor score* & 2005 \\
\hline SES quintile & MCA factor score* & 2005 \\
\hline Regional fertility & Province-level TFR (2000) & 2005 \\
\hline
\end{tabular}

Notes:

2000 dataset: county-level average of 2000 census variables $(n=2,368$ counties)

2005: household and mother variables of births during the last 12 months reported by women aged 15-49 years in the 2005 survey ( $n=24,898$ births)

PCA (principal component analysis) and MCA (multiple correspondence analysis) methodology described in the text 


\section{REFERENCES}

Abdi, Hervé and Dominique Valentin (2007) 'Multiple Correspondence Analysis', in Neil J. Salkind (ed.) Encyclopedia of Measurement and Statistics, pp. 651-57. Thousand Oaks, CA: Sage Publications.

Agnihotri, Satish B. (2003) 'Survival of the Girl Child: Tunnelling out of the Chakravyuha', Economic and Political Weekly 33(41): 4351-60.

Appleton, Simon, Lina Song and Qingjie Xia (2010) 'Growing out of Poverty: Trends and Patterns of Urban Poverty in China 1988-2002', World Development 38(5): $665-78$.

Attané, Isabelle (2007) 'Minorities: Cultural Integration, Family Planning, and Population Changes', in Zhongwei Zhao and Fei Guo (eds) Transition and Challenge: China's Population at the Beginning of the 21st Century, pp. 251-70. Oxford: Oxford University Press.

Attané, Isabelle (2009) 'The Determinants of Discrimination against Daughters in China: Evidence from a Provincial-level Analysis', Population Studies 63(1): 87-102.

Attané, Isabelle and Christophe Z. Guilmoto (eds) (2007) Watering the Neighbour's Garden. The Growing Demographic Female Deficit in Asia. Paris: CICRED.

Banister, Judith (2004) 'Shortage of Girls in China Today', Journal of Population Research 21(1): 19-45.

Bhat, P.N Mari and A.J. Francis Zavier (2007) 'Factors Influencing the use of Prenatal Diagnostic Techniques and Sex Ratio at Birth in India', in Isabelle Attané and Christophe Z. Guilmoto (eds) Watering the Neighbour's Garden. The Growing Demographic Female Deficit in Asia, pp. 135-64. Paris: CICRED.

Bhattacharjya, Debarun, Anant Sudarshan, Shripad Tuljapurkar, Ross Shachter and Marcus Feldman (2008) 'How Can Economic Schemes Curtail the Increasing Sex Ratio at Birth in China?', Demographic Research 19(54): 1831-50.

Bossen, Laurel (2007) 'Missing Girls, Land and Population Controls in Rural China', in Isabelle Attané and Christophe Z. Guilmoto (eds) Watering the Neighbour's Garden. The Growing Demographic Female Deficit in Asia, pp. 207-29. Paris: CICRED.

Cai, Fei (2007) 'Factor-specific Contribution Rate of the Rising Sex Ratio at Birth in China' [in Chinese], Chinese Journal of Population Research 31(4): 9-19.

Cai, Yong and William Lavely (2007) 'Child Sex Ratios and their Special Variation', in Zhongwei Zhao and Fei Guo (eds) Transition and Challenge: China's Population at the Beginning of the 21st Century, pp. 108-23. Oxford: Oxford University Press.

Casterline, John B. (ed.) (2001) Diffusion Processes and Fertility Transition. Selected Perspectives. Washington, DC: National Academy Press.

Chahnazarian, Anouch (1988) 'Determinants of the Sex Ratio at Birth: Review of Recent Literature', Social Biology 35(3-4): 214-35.

Chen, Shengli, Faming Gu and Fei Cai (2008) 'Enlightenments from the 2005 One Per Cent Population Survey for Addressing the Abnormally High Sex Ratio at Birth in China' [in Chinese], Chinese Journal of Population Research 32(1): 22-33.

Chu, Junhong (2003) 'Prenatal Sex Determination and Sex-selective Abortion in Rural Central China', Population and Development Review 27(2): 259-81.

Chun, Heeran, Il-Ho Kim and Young-Ho Khang (2009) 'Trends in Sex Ratio at Birth according to Parental Social Positions: Results from Vital Birth Statistics, 1981-2004 in Korea' [in Korean], Journal of Preventive Medical Public Health 42(2): 143-50.

Chung, Woojin and Monica Das Gupta (2007) 'The Decline of Son Preference in South Korea: The Roles of Development and Public Policy', Population and Development Review 33(4): 757-83.

Croll, Elisabeth (2000) Endangered Daughters: Discrimination and Development in Asia. New York: Routledge.

Das Gupta, Monica (2010) 'Family Systems, Political Systems and Asia's "Missing Girls": The Construction of Son Preference and its Unravelling', Asian Population Studies 6(2): $123-52$. 
Das Gupta, Monica, Woojin Chung and Shuzhuo Li (2009) 'Evidence of an Incipient Decline in Numbers of Missing Girls in China and India', Population and Development Review 35(2): 401-15.

Ebenstein, Avraham and Steven Leung (2009) 'Son Preference and the Missing Market for Social Insurance: Evidence from China's Rural Pension Program'. Paper presented at the annual meeting of the Population Association of America, Detroit (30 April-2 May).

Eklund, Lisa (2011) “"Good Citizens Prefer Daughters”: Gender, Rurality and the Care for Girls Campaign', in Tamara Jacka and Sally Sargeson (eds) Women, Gender and Development in Rural China, pp. 124-42. Cheltenham: Edward Elgar.

Fan, C. Cindy (2008a) 'Migration, Hukou, and the Chinese City', in Shahid Yusuf and Tony Saich (eds) China Urbanizes: Consequences, Strategies, and Policies, pp. 65-90. Washington, DC: The World Bank.

Fan, C. Cindy (2008b) China on the Move: Migration, the State, and the Household. London: Routledge.

Fan, C. Cindy and Mingjie Sun (2008) 'Regional Inequality in China, 1978-2006', Eurasian Geography and Economics 48(1): 1-20.

Greenhalgh, Susan and Edwin A. Winckler (2005) Governing China's Population: From Leninist to Neoliberal Biopolitics. Palo Alto, CA: Stanford University Press.

$\mathrm{Gu}$, Baochang and Krishna Roy (1995) 'Sex Ratio at Birth in China, with Reference to Other Areas in East Asia: What We Know', Asia-Pacific Population Journal 10(3): 17-42.

$\mathrm{Gu}$, Baochang and Yi Xu (1994) 'A Roundup of the Sex Ratio at Birth in China' [in Chinese], Chinese Journal of Population Science 3: 41-8.

Gu, Baochang, Feng Wang, Zhigang Guo and Erli Zhang (2007) 'China's Local and National Fertility Policies at the End of the Twentieth Century', Population and Development Review 33(1): 129-47.

Guilmoto, Christophe Z. (2005) 'A Spatial and Statistical Examination of Child Sex Ratio in China and India', in Isabelle Attané and Jacques Véron (eds) Gender Discrimination in Asia, pp. 133-67. Pondicherry: IFP-Ceped.

Guilmoto, Christophe Z. (2008) 'Economic, Social and Spatial Dimensions of India's Excess Child Masculinity', Population 63(1): 91-118.

Guilmoto, Christophe Z. (2009) 'The Sex Ratio Transition in Asia', Population and Development Review 35(3): 519-49.

Guilmoto, Christophe Z. and Sébastien Oliveau (2007) 'Sex Ratio Imbalances among Children at Micro-level: China and India Compared'. Paper presented at the Annual Meeting of the Population Association of America, New York (28-31 March).

Guo, Zhigang (2007) 'Multilevel Analysis of Sex Ratio at Birth in China 2000 Population Census' [in Chinese], Chinese Journal of Population Research 31(3): 20-31.

Han, Shihong and Shuzhuo, Li (1999) 'Effect of Individual and Household Factors on Sex Differences in Child Survival in China' [in Chinese], Population and Economics 2: 28-34.

Jha, Prabhat et al. (2011) 'Trends in Selective Abortions of Girls in India: Analysis of Nationally Representative Birth Histories from 1990 to 2005 and Census Data from 1991 to 2011', The Lancet 377(9781): 1921-8. DOI: 1016/S0140-6736(11)60649-1

Kim, Doo-Sub and Yoo-Jean Song (2007) 'Does Religion Matter? A Study of Regional Variations in Sex Ratio at Birth in Korea', in Isabelle Attané and Christophe Z. Guilmoto (eds) Watering the Neighbour's Garden. The Growing Demographic Female Deficit in Asia, pp. 183-207. Paris: CICRED.

Lavely, William and Yong Cai (2004) 'Spatial Variation of Juvenile Sex Ratios in the 2000 Census of Chin'. Paper presented at the Annual Meeting of the Population of Association of America, Boston (1-3 April).

Li, Nan, Marcus W. Feldman and Shripad Tuljapurkar (2000) 'Sex Ratio at Birth and Son Preference', Mathematical Population Studies 8(1): 91-107.

Li, Shuzhuo (2007) 'Imbalanced Sex Ratio at Birth and Comprehensive Intervention in China'. Paper presented at the 4th Asia Pacific Conference on Reproductive and Sexual Health and Rights, Hyderabad, India (29-31 October). http://www.unfpa.org/gender/case_studies.htm 
Li, Shuzhuo and Chuzhu Zhu (2001) Research and Community Practices on Gender Differences in Child Survival in China [in Chinese]. Beijing: China Population Press.

Li, Shuzuo, Marcus W. Feldman and Nan Li (2000) 'Cultural Transmission of Uxorilocal Marriage in Lueyang, China', Journal of Family History 25(2): 158-77.

Li, Shuzhuo, Yan Wei, Quanbao Jiang and Marcus W. Feldman (2007) 'Imbalanced Sex Ratio at Birth and Female Child Survival in China: Issues and Prospects', in Isabelle Attané and Christophe Z. Guilmoto (eds) Watering the Neighbour's Garden. The Growing Female Demographic Deficit in Asia, pp. 25-48. Paris: CICRED.

Li, Yongping (1993a) 'Effect of Selective Abortion on Sex Ratio at Birth' [in Chinese], Chinese Journal of Population Research 5: 21-25, 13.

Li, Yongping (1993b) 'Relationship Between Sex Ratio at Birth and Socio-economic Factors: Census Results and its Facts' [in Chinese], Chinese Journal of Population Research 4: 3-13.

Lin, Tin-chi (2009) 'The Decline of Son Preference and the Rise of Gender Indifference in Korea and Taiwan since 1990'. Paper prepared for the IUSSP International Population Conference, Marrakech (27 September-2 October).

Lv, Hongping (2003) 'Studies on Recent Rising in Sex Ratio at Birth in China' [in Chinese]. Paper presented at the Symposium of Population and Development of Constructing a Comprehensive Well-off Society, Changchun, China (25 September).

Ma, Zhengliang (1997) 'The Practice of Living with the Bride's Family and Fertility Decline in Rural Gansu', in China Population Association (ed.) Proceedings of the 23rd IUSSP General Population Conference Symposium on Demography of China, pp. 325-32. Beijing.

Miller, Barbara D. (2001) 'Female-selective Abortion in Asia: Patterns, Polices, and Debates', American Anthropologist 103(4): 1083-95.

Nielsen, Ingrid, Russell Smyth, Mingqiong Zhang and Cherrie Jiuhua Zhu (2005) 'Which Rural Migrants Receive Social Insurance in Chinese Cities? Evidence from Jiangsu Survey Data', Global Social Policy 5(3): 353-81.

Nielsen, I., C. Nyland, R. Smyth and C. Zhu (2005) 'Marketization and Perceptions of Social Protection in China's Cities', World Development 33(11): 1759-81.

NSB (National Statistics Bureau) (2004) Women and Men in China. Facts and Figures 2004. Beijing: China Statistics Press.

NSB (National Statistics Bureau) (2007) Tabulation of the 2005 National 1\% Population Sample Survey. Beijing: China Statistics Press.

NSB (National Statistics Bureau) (2008) Proceedings of Studies on 2005 National 1\% Population Sample Survey [in Chinese]. Beijing: China Statistics Press.

NSB (National Statistics Bureau) (2009) China Population and Employment Statistics Yearbook 2009. Beijing: China Statistics Press.

NSB (National Statistics Bureau) (2010) 'Statistical Communiqué of the People's Republic of China on the 2009 National Economic and Social Development'. http://www.stats.gov.cn/ english/newsandcomingevents/t20100226_402623115.htm.

O'Keefe, Philip and Dewen Wang (2010) 'Closing the Coverage Gap: Evolution and Issues for Rural Pensions in China'. Paper presented at the conference 'The Challenges of Population Ageing in Asia', Chinese Academy of Social Sciences, Beijing (8-10 December).

Qi, Yaqiang and William M. Mason (2005) Prenatal Sex-selective Abortion and High Sex Ratio at Birth in Rural China: A Case Study in Henan Province. UC Los Angeles: California Center for Population Research. Available at: http://www.escholarship.org/uc/item/8j01443f

Retherford, Robert D. and Tarun K. Roy (2003) 'Factors Affecting Sex-selective Abortion in India and 17 Major States'. NFHS Subject Reports 21. Mumbai and Honolulu: International Institute for Population Sciences and East-West Center.

Salditt, Felix, Peter Whiteford and Willem Adema (2008) 'Pension Reform in China', International Social Security Review 61(3): 47-71.

Samir, K.C., Bilal Barakat, Anne Goujon, Vegard Skirbekk and Wofgang Lutz (2008) 'Projection of Populations by Level of Educational Attainment, Age and Sex for 120 Countries for 20052050'. IIASA Interim Report IR-08-038. Luxenburg: International Institute for Applied Systems Analysis. 
Selden, Mark and Laiyin You (1997) 'The Reform of Social Welfare in China', World Development 25(10) 1657-68.

Sharping, Thomas (2003) Birth Control in China 1949-2000: Population Policy and Demographic Development. London: Routledge-Curzon.

Sheng, Xuewen (2005) 'Chinese Families', in Bert N. Adams and Jan Trost (eds) Handbook of World Families, pp. 99-128. Thousand Oaks, CA: Sage Publications.

Siddhanta, S., D. Nandy and S.B. Agnihotri (2003) 'Sex Ratios and "Prosperity Effect": What Do NSSO Data Reveal?', Economic and Political Weekly 38(41): 4381-404.

Solinger, Dorothy J. (1999) Contesting Citizenship in Urban China: Peasant Migrants, the State, and the Logic of the Market. Berkeley, CA: University of California Press.

Steel, David G., Mark Tranmer and D. Tim Holt (2006) 'Unravelling Ecological Analysis', Journal of Applied Mathematics and Decision Sciences 2006: 1-18. Article ID 38358. DOI:10.1155/JAMDS/2006/38358

Tan, Liang Ying (2008) 'Changing Mindsets: How China's Abnormal Sex Ratio is Turning its Government into a Champion of Gender Equality', Asian Journal of Comparative Law 3(1). Article 2. DOI: 10.2202/1932-0205.1039

Teitelbaum, Michael S. and Nathan Mantel (1971) 'Socio-economic Factors and the Sex Ratio at Birth', Journal of Biosocial Science 3: 23-41.

UNDP (2005) China Human Development Report 2005: Towards Human Development with Equity. New York: UNDP.

UNFPA (2010) Sex Ratio at Birth Imbalances in Viet Nam: Evidence from the 2009 Census. Hanoi: UNFPA.

Wang, Feng (2003) 'Housing Improvement and Distribution in Urban China: Initial Evidence from China's 2000 Census', China Review 3(2): 121-43.

World Bank (2009) 'From Poor Areas to Poor People: China's Evolving Poverty Reduction Agenda. An Assessment of Poverty and Inequality in China'. Poverty Reduction and Economic Management Department, East Asia and Pacific Region. http://siteresources. worldbank.org/CHINAEXTN/Resources/318949-1239096143906/China_PA_Report_ March_2009_eng.pdf

Wu, Haixa, Marcus W Feldman, Xiaoyi Jin and Shuzhuo Li (2007) 'Social Networks and Son Preference among Rural-Urban Migrants in China: A Study in Shenzhen', in Isabelle Attané and Christophe Z. Guilmoto (eds) Watering the Neighbour's Garden. The Growing Demographic Female Deficit in Asia, pp. 247-65. Paris: CICRED.

Wu, Zhuochun, Kirsi Viisainen and Elina Hemminki (2006) 'Determinants of High Sex Ratio among Newborns: A Cohort Study from Rural Anhui Province, China', Reproductive Health Matters 14(27): 172-80.

Yuan, Xin and Hailong Shi (2005) 'Abnormally High Sex Ratio at Birth and the Fertility Planning Policy in China' [in Chinese], Chinese Journal of Population Research 29(3): 11-17.

Zeng, Yi (2002) 'Marriage Patterns in Contemporary China', in Xize Peng and Zhigang Guo (eds) The Changing Population of China, pp. 91-100. Oxford: Blackwell Publishers.

Zeng, Yi (2007) 'Options for Fertility Policy Transition in China', Population and Development Review 33(2): 215-46.

Zeng, Yi and Zhenglian Wang (2003) 'Dynamics of Family and Elderly Living Arrangements in China: New Lessons Learned From the 2000 Census', The China Review 3(2): 95-119.

Zeng, Yi, Ping Tu, Baochang Gu, Yi Xu, Bohua Li and Yongping Li (1993) 'Causes and Implications of the Recent Increase in the Reported Sex Ratio at Birth in China', Population Development Review 19(2): 283-302.

Zhang, Erli (2005) 'Impact of Policy Fertility on Sex Ratio at Birth and Infant Mortality: Investigation at the City and Prefecture Level' [in Chinese], Chinese Journal of Population Research 29(1): 11-18.

Zhang, Guangyu and Baochang Gu (2007) 'Recent Changes in Marriage Patterns', in Zhongwei Zhao and Fei Guo (eds) Transition and Challenge: China's Population at the Beginning of the 21st Century, pp. 124-39. Oxford: Oxford University Press. 
Zhao, Zhongwei and Fei Guo (eds) (2007) Transition and Challenge: China's Population at the Beginning of the $21^{\text {st }}$ Century. Oxford: Oxford University Press.

Zheng, Zhenzhen (2007) 'Interventions to Balance Sex Ratio at Birth in Rural China', in Isabelle Attané and Christophe Z. Guilmoto (eds) Watering the Neighbour's Garden. The Growing Demographic Female Deficit in Asia, pp. 327-46. Paris: CICRED.

Zhu, Weixing, Li Lu and Therese Hesketh (2009) 'China's Excess Males, Sex Selective Abortion, and One-Child Policy: Analysis of Data from 2005 National Intercensus Survey', British Medical Journal 338: b1211. DOI: 10.1136/bmj.b1211

Christophe Z. Guilmoto is senior fellow at IRD-CEPED (19 rue Jacob, Paris, F-75020, France; e-mail: Christophe.guilmoto@ird.fr.) and teaches at Université Paris-Descartes and at EHESS in Paris. He has published books and papers on migration, spatial demography and India's population, with a recent focus on various aspects of pre-natal sex selection in Asia.

Qiang Ren is at the Institute of Population Research, Peking University, Beijing 100871, PR China (e-mail: renqiang@pku.edu.cn). His research interests include population, environment and health, demography, issues on fertility, mortality and labour force, focusing primarily upon demography and quantitative methodology. 